\title{
ORDEM SOCIAL E PRÁTICAS AGRÍCOLAS: A FRANÇA COMO FONTE INSPIRADORA DE PROJETOS DE COLÔNIAS AGRÍCOLAS NO BRASIL IMPÉRIO
}

\author{
Inoã Pierre Carvalho Urbinati*
}

\begin{abstract}
Resumo: A leitura de diversos documentos mostra que a conhecida influência francesa no Brasil imperial parece ter se manifestado também em propostas de criação de colônias agrícolas, tendo havido inclusive referência à célebre colônia penal e agrícola de Mettray. Esse fenômeno se verificou também, no Brasil, quando dos debates em torno dos futuros libertos, num contexto de progressiva extinção da escravidão. $\mathrm{O}$ artigo tem como proposta investigar a presença francesa na elaboração de projetos de colônias agrícolas, tanto relacionadas ao meio judiciário, como aquelas voltadas prioritariamente para os planos de pós-abolição, procurando ver em que medida um espírito modernizador norteou esses projetos, ao mesmo tempo em que transparecia uma preocupação de controle social.
\end{abstract}

Palavras-chave: Império. Colônias agrícolas. França.

Social order and agricultural practices: France as inspiring source of agricultural settlements projects in Brazil's Imperial times

Abstract: The reading of several documents shows that the well-known French influence in Brazil, during the Imperial Government, also seems to have manifested itself in proposals for the creation of agricultural colonies; and there was even a reference to the famous penal and agricultural colony of Mettray. This phenomenon is also found, in Brazil, when there were debates about the people intended to be set free, in a context of gradual extinction of slavery. The article proposes to investigate the French presence in the elaboration of agricultural colonies projects, both those related to the judiciary realm and the ones primarily aimed at post-abolition plans, trying to see at what extent a modernizer spirit guided these projects, and, at the same time, transpired that there was a concern for social control.

Keywords: Empire. Agricultural colonies. France.

* Universidade do Estado do Rio de Janeiro - UERJ, Rio de Janeiro-RJ, Brasil (inoacarvalho@yahoo.com).

Recebido em: 20/10/2014 - Aceito em: 15/06/2015. 
|254 |

Ordem social e práticas...

Orden social y prácticas agrícolas: Francia como fuente inspiradora de proyectos de colonias agrícolas en Brasil Imperio

Resumen: La lectura de diversos documentos muestra que la conocida influencia francesa en Brasil imperial parece que se ha manifestado también en las propuestas para establecer colonias agrícolas, habiendo incluso referencia a la célebre colonia penal y agrícola de Mettray. Este fenómeno se verificó también en Brasil, cuando hubo discusiones alrededor de los futuros libertos, en un contexto de extinción progresiva de la esclavitud. El artículo se propone a investigar la presencia francesa en la elaboración de proyectos de colonias agrícolas, tanto relacionados con los medios judiciarios, como aquellos orientados principalmente a los planes de post-abolición, buscando ver en qué medida un espíritu modernizador ha guiado estos proyectos, al mismo tiempo que translucía una preocupación por el control social.

Palabras clave: Imperio. Colonias agrícolas. Francia.

Ao longo do século XIX, e até o início do século XX, como é de conhecimento antigo da historiografia, a França exerceu uma forte influência cultural na sociedade brasileira, notadamente junto às suas elites letradas, fenômeno registrado por diversos pesquisadores, como Mário Corelli (CORELLI, 1994), Nelson Schapochnik (SCHAPOCHNIK, 1999), eTânia BessoneFerreira, que mencionou a presença de obras francesas nas bibliotecas privadas do Rio de Janeiro oitocentista (FERREIRA, 1999). Influência essa também registrada no campo da política, como, por exemplo, com o positivismo. Outro setor conheceu uma importante influência francesa, ainda que até agora, aparentemente pouco estudado: a agricultura e as atividades a ela relacionadas.

Ora, em diversos textos da época, se percebe uma constante referência a autores franceses ou a aspectos da política agrícola francesa, para fundamentar projetos agrários, como no caso do renomado engenheiro abolicionista André Rebouças, e também de outros personagens influentes do Segundo Reinado, como Nabuco de Araújo, Joaquim Nabuco e Tavares Bastos.

Neste texto nos deteremos especificamente em projetos envolvendo a implantação de colônias agrícolas, algumas das quais de caráter penal, observando particularmente projetos desenvolvidos por Nabuco de Araújo e relatórios do Ministério da Justiça. A consulta a diversas fontes (livros, periódicos, relatórios 
ministeriais) permite, de fato, que se perceba uma alusão frequente à França.

Focalizaremos aqui o Segundo Reinado, especialmente as últimas décadas do regime monárquico, num contexto de progressiva dissolução do regime escravista e advento do trabalho "livre", ocasião em que foram travados importantes e numerosos debates em torno da questão agrária e da mão de obra e período marcado pela adoção de medidas abolicionistas, como a Lei do Ventre Livre (1871), emancipando os filhos dos escravos, e a própria Lei Áurea (1888), que formalmente aboliu a escravatura no país.

Aqui abordamos projetos de colônias agrícolas voltadas para detentos e outras voltadas para os filhos de escravos. Também é importante salientar o fato de que o país permaneceu, ao longo de todo o século - e em grande parte ainda atualmente - marcado pelo predomínio da grande propriedade agrária, devendo-se registrar o fim do regime das sesmarias em 1822 e a promulgação da lei 601, a chamada Lei de Terras, em setembro de 1850, visando regularizar o sistema fundiário, e determinando a compra como única forma de obtenção de terra.

Esta lei na opinião de muitos historiadores teve como efeito, sobretudo, dificultar o acesso a terra por parte dos setores mais humildes e em benefício dos grandes proprietários rurais, mas Márcia Motta, sem deixar de reconhecer o peso político desse setor na aprovação da lei, observou que a lei estava longe de corresponder a uma mera imposição desse grupo e que, fruto de conflitos entre diferentes interesses, era passível de diversas interpretações, inclusive por parte dos pequenos lavradores e camponeses, que por meio de alguns artigos da Lei de Terras, poderiam eventualmente obter algumas vitórias, lembrando a autora, com base no britânico E. Thompson, a complexidade que envolve a formulação de uma lei e os conflitos políticos a ela relacionados (MOTTA, 1998).

Por outro lado, ainda que de uma forma regional (é importante observar esse aspecto), sobretudo, foram adotadas algumas medidas favoráveis à implantação de colônias agrícolas 
| 256 |

Ordem social e práticas...

no país. Assim, e após uma pioneira experiência de colonização europeia com base na pequena propriedade fundiária, em Nova Friburgo (RJ), em 1818-1820, foram instituídas diversas colônias agrícolas no país, sobretudo no Sul (GUIMARÃES, 1989), especialmente na segunda metade do século.

Levando em conta o fato de que as colônias agrícolas de que nos ocupamos neste trabalho dizem respeito a estabelecimentos criados pelo Estado, havendo, portanto, uma presença fundamental do poder estatal, nós procuraremos desvelar o sentido de sua formação, e tentaremos compreender de que forma elas faziam parte de um projeto que buscava ordenar a sociedade, dentro de um contexto brasileiro marcado pela transição do trabalho escravo para o livre, e no qual não faltaram debates em torno de medidas para se garantir a "ordem pública" na nova ordem pós-escravista que se estava estabelecendo. Esta consideração não induz a uma classificação prévia dos projetos de colônias agrícolas como possuindo um traço essencialmente conservador, mas sim a avaliálas de forma crítica, sem deixar de perceber outras conotações.

Por sua vez, o conceito de colônia agrícola pode ser apreendido basicamente enquanto o "núcleo colonial, o conjunto de lotes rurais e urbanos e a infraestrutura deste núcleo" (GREGORY, 2005: 96). Este conceito nos parece bastante claro, servindo bem para definir as colônias agrícolas que efetivamente foram implantadas em algumas regiões do país sob o Império - especialmente no Sul, tendo como integrantes principalmente imigrantes europeus -, mas no nosso estudo é preciso ter em mente uma presença ainda mais marcante do poder estatal ao seio das colônias, visto que seus integrantes, pela sua própria condição jurídica - detentos de um lado, e ingênuos (crianças filhas de pais escravizados) de outro ficavam sujeitos a uma tutela muito mais nítida por parte do poder público, por motivos bastante óbvios.

É preciso, ainda, esclarecer que nos ocuparemos aqui de projetos de colônias agrícolas, voltadas para libertos e filhos de escravos, isto é, de planos, que em grande parte não chegaram a se efetivar concretamente, mas que, porém, ajudam a entender a percepção governamental em relação aos indivíduos 
juridicamente colocados sob sua tutela, num contexto histórico marcado pela perspectiva de abolição da escravidão. Feitas essas considerações, é preciso observar que o texto está dividido em duas partes principais: analisaremos primeiramente projetos de colônias agrícolas e penais, e, em um segundo momento, projetos de colônias agrícolas relacionadas a uma política de emancipação.

Abordaremos, portanto, primeiramente, a política oficial voltada para o estabelecimento de colônias agrícolas na França, focalizando aquelas vinculadas ao setor penal. Com base em alguns nomes da historiografia francesa, apresentaremos alguns dados marcantes da realidade francesa e indicaremos algumas das principais colônias efetivamente instituídas, de forma a melhor compreender suas repercussões, no Brasil, que analisaremos através de documentos relacionados ao senador Nabuco de Araújo. Já num segundo momento, o foco da nossa atenção recairá na política de emancipação, buscando mostrar as vinculações existentes entre a política brasileira - sobretudo projetos - e medidas adotadas pelo governo francês no que diz respeito às suas áreas coloniais nas Antilhas, especialmente sob a Monarquia de Julho (1830-1848), quando se debatia a gradativa extinção do regime escravista.

No início do século XIX, começaram a ser implantadas colônias agrícolas na França. A agricultura constituía então o setor dominante da economia, e a estrutura fundiária era marcada por uma importante presença da pequena propriedade agrária, que, de certa forma, foi favorecida e até consolidada com a Revolução Francesa (ASSELAIN, 1984: 117) e com a promulgação do Código Civil, em 1804, sob o governo de Napoleão Bonaparte (MOULIN, 1988: 57), se expandindo ao longo do século XIX. Em 1807, foi instituído o Cadastro Fundiário, cuja execução estendeuse basicamente até meados do século. $\mathrm{Na}$ primeira metade do Oitocentos, os progressos da agricultura francesa revelaram-se relativamente modestos (MOULIN, 1988: 69), devendo-se de todo modo ressaltar o advento do arado de Dombasle, assim denominado por ter sido difundido pelo agrônomo Mathieu de Dombales (1777-1843), a partir da década de 1820 (KNITTEL, 2009). Os primeiros projetos de colônias agrícolas começaram 
a ser divulgados neste período. Em 1832, o agrônomo e exdeputado Huerne de La Pommeuse publicou Des colonies agricoles et de leurs avantages ("Das colônias agrícolas e de suas vantagens") (FOUGÈRE, 2002: 37).

A defesa de criação desse tipo de estabelecimento vinculouse, nesse momento, na França, aos debates concernentes ao setor penitenciário, sendo as colônias vistas como uma alternativa ao sistema penal, objeto de estudo de vários pesquisadores franceses da época, sobretudo durante a Monarquia de Julho (1830-1848). Os primeiros defensores da solução agrícola, como Haussez e o já citado Huerne de la Pommeuse, visaram ocupar os colonos crianças desamparadas, órfãos, mendigos, jovens delinquentes, etc. - em atividades agrícolas, objetivando aproveitar as superfícies cultiváveis (JABLONKA, 2005: 77). E, ao longo do século XIX, diversas colônias agrícolas foram instituídas na França, estimuladas pelo poder público, sobretudo através de uma lei votada em 5 de agosto de 1850, consagrando o desenvolvimento de colônias penitenciárias e agrícolas (PRADE, 2005: 33), direcionadas especialmente para menores infratores, e que repercutiu no Brasil, sendo um exemplo desta repercussão a menção feita pelo reputado Jornal do Commercio à referida lei, como medida a ser examinada pelo governo brasileiro, na primeira página da edição de 15 de março de 1878 (JORNAL DO COMMERCIO, 1987: 108).

De acordo com o historiador Ivan Jablonka, a colônia penal e agrícola, tida por ele como "laboratório de pesquisa agronômica", deveria oferecer uma solução a todos os problemas sociais: conter o êxodo rural, modernizar a agricultura e reerguer pequenos cidadãos corrompidos oferecendo-lhes uma formação técnica (JABLONKA, 2005: 78).

Dentre as colônias agrícolas instituídas na França, citam-se: colônia de Saint-Bernard (criada em 1844 sob a denominação Loos e batizada Saint-Bernard em 1862); colônia de Clairvaux (instituída em 1843); colônia de Fontevrault (Boulard), dentre várias outras (PRADE, 2005: 32-35). Deve-se, ainda, destacar o nome do inspetor de prisões Charles Lucas, que muito atuou na defesa da solução agrária como alternativa no sistema penal, e visto mesmo por 
Catherine Prade como o responsável principal pelo movimento do qual emergiram as colônias agrícolas (PRADE, 2005: 31-32).

Percebe-se que as colônias encontraram uma importante receptividade ao seio da classe política francesa, e deve-se notar, inclusive, o fato de que Luís Bonaparte (1808-1873), futuro Napoleão III, quando de sua prisão, entre 1840 e 1846, pelo governo do Rei Luís Felipe I, projetou a criação de colônias agrícolas a serem ocupadas por detentos, em L'Éxtinction du Paupérisme ("A Extinção do Pauperismo"). Abordaremos a seguir o eco das colônias penais e agrícolas francesas ao seio da elite política brasileira imperial, isto é, apresentaremos dados revelando projetos voltados para o setor penal tendo como inspiração os estabelecimentos penitenciários franceses voltados para a "recuperação" dos indivíduos por meio das práticas agrícolas.

A leitura de um grande clássico da historiografia brasileira, Um Estadista do Império, redigido pelo abolicionista, historiador e diplomata Joaquim Nabuco (1849-1910), bem como a de relatórios ministeriais, permite observar a posição de um importante estadista do Segundo Reinado e pai do abolicionista, Tomás Nabuco de Araújo (1813-1878) em relação à ideia de colônias agrícolas, em duas áreas de sua atuação: no projeto de reforma judiciária e no de emancipação dos escravos. Nabuco de Araújo, jurista de formação, ocupou diversas vezes o cargo de Ministro da Justiça, e nessa condição se debruçou em propostas de reforma do sistema penitenciário.

Deve-se observar o contexto de discussões em torno de modelos penais a serem instituídos no Brasil, que caracterizou a área de direito no Brasil oitocentista, conforme analisado por pesquisadores como Myrian Sepúlveda dos Santos, que, inclusive, mencionou diretamente Nabuco de Araújo, quando de sua primeira passagem pela pasta da Justiça na década de 1850 (SANTOS, 2009: 58). Santos, que observou como as condições precárias das prisões brasileiras no século XIX levaram a que fossem formuladas propostas de modificações do setor judiciário e penal, citou inclusive a França, como um dos países, assim como os Estados Unidos da América, em que se utilizava a pena de degredo 
| 260 |

Ordem social e práticas...

para lugares distantes, como ocorreria no Brasil, sobretudo com a instalação de presídios em ilhas (SANTOS, 2009: 59).

A proposta de reforma penitenciária apoiada por Nabuco de Araújo pode ser apreendida com base no relatório referente ao ano de 1865 e apresentado em 1866, quando de sua última passagem pelo Ministério da Justiça, durante o gabinete presidido por Pedro de Araújo Lima, o Marquês de Olinda (FIRMO; OCTACIANO, 1973: 670). Como observaremos um pouco adiante, o senador aludiu à França, como modelo para a introdução das reformas preconizadas. No relatório de 1866, Nabuco propôs uma reforma concernente à pena de galés, cuja aplicação se fazia então, segundo o relatório de Nabuco, nas cadeias das cidades e vilas, e que se achavam em "deplorável estado" (RELATÓRIO DO MINISTÉRIO DA JUSTIÇA, 1866: 48). Uma das propostas de Nabuco era a substituição da pena de galés pela instituição de colônias penais.

Nabuco então encarregou Felipe Lopes Neto de estudar na Europa os "resultados das colônias penais" (NABUCO, 1997: 643). Este, porém, não os achou satisfatórios. De acordo com Joaquim Nabuco,

\footnotetext{
Lopes Neto faz uma visita a diversos estabelecimentos penais europeus e procede a uma espécie de inquérito entre as autoridades as mais competentes; a sua conclusão é de todo desfavorável às colônias agrícolas que Nabuco desejava instituir. Parece-lhe mesmo que em Fernando de Noronha seria mal aconselhada qualquer tentativa de colonização (NABUCO, 1997: 643).
}

A despeito do pouco entusiasmo demonstrado por Lopes pelas colônias, Nabuco continuou defendendo a ideia das colônias penais. Observe-se que as colônias penais a serem introduzidas incluiriam o trabalho agrícola: Joaquim Nabuco falou claramente em "colônias agrícolas" que seu pai "desejava instituir". Realmente, nas colônias penais pensadas por Nabuco, uma das medidas a ser instauradas seria o trabalho agrícola - fato especialmente marcante numa sociedade como a do Brasil oitocentista, onde a grande 
maioria da população vivia no campo. É importante lembrar, também, que a proposta de criação de colônias penais e agrícolas esteve presente no discurso de outras personalidades do período imperial, e que se chegou a instituir, durante o Império, uma colônia penal e agrícola na Ilha de Fernando de Noronha (SANTOS, 2009: 61), embora a experiência tenha se revelado frustrante em muitos aspectos, devido a fatores como corrupção e falta de organização.

As posições de Nabuco de Araújo quanto ao setor penal inserem-se no quadro de um agudo debate travado durante boa parte do Segundo Reinado relativo a uma reforma do sistema penitenciário. Ao se examinar relatórios de outros ministros da Justiça, percebe-se a presença de referências francesas, inclusive quanto a colônias agrícolas. Deve-se lembrar a esse respeito, a existência, naquele país, da célebre colônia penal de Mettray, que, instituída na região do Indre-et-Loire (e perto da cidade de Tours) em 1839, em meio a um rígido controle dos internos (FOUCAULT, 2008: 243-254), incluía práticas agrícolas. A colônia, ao longo de quase cem anos de existência (1839-1937), alcançou grande repercussão na França e, inclusive, no Brasil, especialmente quando dos debates em torno de uma reforma do sistema penitenciário na década de 1870, como se pode perceber no seguinte trecho do Relatório do Ministro da Justiça Diogo Velho Cavalcanti de Albuquerque, de 1875, apresentado à Assembleia Geral Legislativa do Império: "Resta fundar estabelecimentos, com a disciplina severa de Mettray na França, Red Hill na Inglaterra, ou de Saint Hubert, na Bélgica" (RELATÓRIO DO MINISTÉRIO DA JUSTIÇA, 1875: 45).

Mettray, instituição criada por filantropos, especialmente por Fréderic Demetz, e contando inicialmente com forte apoio de setores da elite política e jurídica francesa, constituiu-se numa colônia para onde eram enviados jovens acusados de delitos, para nela permanecerem por um tempo, sob um rígido controle e empregados em atividades agrícolas. A colônia, que chegou a ser visitada pessoalmente por Joaquim Nabuco em 1874, conheceu um período de ascensão, até a década de 1870, quando depois começou 
a declinar gradativamente, sendo frequentes então denúncias de maus tratos aos internos.

Em relação ao setor agrícola propriamente dito, Mettray parece ter alcançado, ao menos por um tempo, algum sucesso, segundo Ivan Jablonka, que ressaltou sua "vocação agronômica" e sua orientação por uma agricultura científica e "moderna" (JABLONKA, 2005: 77). Mettray, em 1849, acolheu 350 colonos, numa superfície de 202 hectares, alcançando 250 hectares em 1871 e 350 hectares em 1890. Nela se cultivavam cereais, legumes, plantas, além da criação de gado (JABLONKA, 2005: 78). Num relatório anterior, de 1874, na seção correspondente à "reforma penitenciária", encontramos importante referência à opção agrária, com base na França, quando o Ministro da Justiça Manuel Antônio Duarte de Azevedo cita uma frase de Léon Faucher em que este defendia a implantação de colônias enquanto:

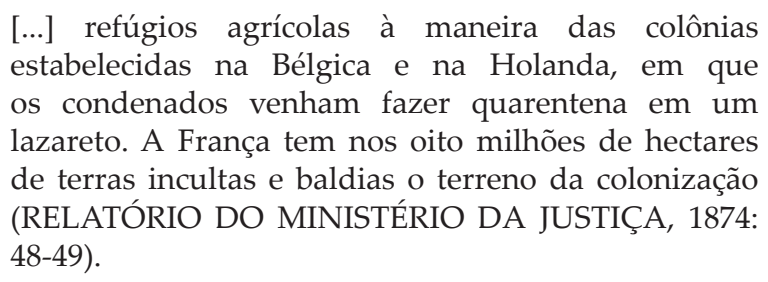
estabelecidas na Bélgica e na Holanda, em que os condenados venham fazer quarentena em um lazareto. A França tem nos oito milhões de hectares de terras incultas e baldias o terreno da colonização (RELATÓRIO DO MINISTÉRIO DA JUSTIÇA, 1874: 48-49).

Voltando ao relatório de Nabuco de Araújo, nas palavras do senador,

[a] colonização penal merece, dizem Duval e Block, as preferências da opinião e da administração; melhor que nenhuma prisão celular ou coletiva, melhor que nenhum trabalho industrial forçado, ela garante a segurança social, pode reformar os criminosos, utilizar os bons instintos que sobrevivem em muitos deles, aproveitar essas forças desviadas da produção agrícola...

A França tem procedido sabiamente inaugurando em suas leis a colonização penal, mas esta empresa 


\begin{abstract}
naufragará se ela não alargar suas vistas. Persistindo os erros atuais, ela não fará senão transportar para além dos mares o - bagne - suprimido no seu continente. "Échec em vez de sucesso"!

Os excelentes resultados que a França e outros países da Europa, como a Bélgica e a Suíça, têm tirado das colônias penais de menores, estabelecidas no continente, torna esperançosa esta aplicação aos adultos (RELATÓRIO DO MINISTÉRIO DA JUSTIÇA, 1866: 49).
\end{abstract}

Verifica-se uma referência elogiosa à França, e ao mesmo tempo crítica, uma vez que Nabuco apontou para os "erros atuais", que podiam levar a ideia das colônias penais ao fracasso. Ele mostra-se, porém, otimista, e citou, na mesma página, os decretos franceses de 1852 e 1853 relativos à supressão do "bagne" (prisão para forçados) e à instituição das colônias penais. Ao mesmo tempo, transparece, no trecho acima destacado, a referência à prática agrícola a ser introduzida nas colônias, tendo Nabuco citado, dentre as vantagens que ele via com a implantação no Brasil das colônias penais, o aproveitamento de "forças desviadas da produção agrícola". Mais adiante, ele propôs as seguintes medidas, para a instituição das colônias:

\footnotetext{
Urge, entretanto: $1^{\circ}$, que a pena de galés, que é a pena normalmente imposta aos crimes graves, ou seja substituída pelas colônias penais, ou seja garantida por estabelecimentos industriais e agrícolas, nas quais ela seja cumprida; $2^{\circ}$, que se estabeleçam colônias agrícolas para educação correcional e repressiva de milhares de menores vadios, e de mendigos e vagabundos que infestam a nossa capital, e prometem tornar-se grandes criminosos; a pena de prisão simples que a lei impõe é funesta, favorece a ociosidade, que é o incentivo deste crime, aumenta a perversidade pelo contato de outros instintos tão perversos ou mais perversos; esta pena é um benefício em vez de ser um mal (RELATÓRIO DO MINISTÉRIO DA JUSTIÇA, 1866: 49).
} 
| 264 |

Ordem social e práticas...

Nota-se um tom hostil à "ociosidade", inclusive relacionado a menores, que na verdade corresponde a um tipo de discurso amplamente disseminado entre os meios governamentais brasileiros oitocentistas, e que se intensificou nas últimas décadas do Império, no contexto de abolição gradual da escravidão, como, aliás, se pode perceber através da leitura de relatórios oficiais, como os de presidentes de província.

Fernando Antônio Lourenço, em Agricultura Ilustrada, examinou a disseminação de um discurso conservador, ao longo do século XIX e presente nas esferas políticas e governamentais, no tocante ao trabalho das classes desfavorecidas da sociedade. A preocupação com uma suposta vadiagem e uma "ociosidade", manifestada por outros governos daquela época, permeou tal discurso, que se referiu tanto à população pobre, de modo geral, como, cada vez mais, aos libertos (LOURENÇO, 2001). Paul Butel, em estudo sobre as Antilhas francesas, assinalou a presença desse discurso repressor no pós-abolição, isto é, na segunda metade do século XIX, com a adoção de medidas coercitivas em relação aos libertos (BUTEL, 2007).

Para Lourenço, muitas medidas, como a criação de colônias penais ou agrícolas, tiveram como propósito principal garantir o trabalho, praticamente compulsório, de amplos setores populares (cujo sentido seria, para ele, a exploração de uma mão de obra barata). Nesse sentido, ele citou a Colônia Agrícola e Penal de Mettray, na França, como fonte de inspiração para tal discurso (LOURENÇO, 2001:175).

Em relação a Nabuco, especificamente, sem negar o vínculo com o discurso relativo à "repressão à ociosidade", acreditamos que a sua motivação para a criação de tais estabelecimentos deve ser compreendida de forma mais ampla, uma vez que ele comungou de ideais emancipacionistas, demonstrando preocupação social, e tendo sido crítico de fundamentos da ordem estabelecida, como o latifúndio, tendo, inclusive sido um partidário declarado da instituição do imposto territorial como forma de subdividir as grandes propriedades rurais incultas (NABUCO, 1997: 996). Além disso, não se deve esquecer que o político defendeu, enquanto 
Ministro da Justiça, a lei conhecida pelo nome Lei Nabuco de Araújo, instituída em 1854 e estabelecendo maior rigor na fiscalização do tráfico de africanos (BOTELHO; REIS, 2001: 261).

Deve-se ainda observar que Lourenço, em seu estudo, ao analisar a proposta de criação de colônias penais, deu ênfase, sobretudo, ao conteúdo conservador que as mesmas possam ter apresentado, uma vez que ele estava preocupado principalmente em desvelar aspectos conservadores do discurso agrário oitocentista. Assim, os projetos de Nabuco (citado diretamente por Lourenço) podem ter sido analisados sem levar em consideração os componentes progressistas do ideário de seu autor, que se manifestaram em diversas ocasiões (LOURENÇO, 2001).

Por outro lado, a presença de traços conservadores em projetos de cunho progressista, com a persistente e intensa preocupação com a preservação da "ordem", fica particularmente nítida quando se aborda a política de emancipação e aquela voltada para o pós-emancipação, isto é, tendo como foco os futuros negros emancipados. Ora, a política emancipacionista do governo imperial foi e tem sido objeto de estudo de diversos pesquisadores. Adiante, focalizaremos alguns dados da questão, buscando entender o sentido das propostas voltadas para a população negra que seria emancipada, e mostrando a presença francesa por trás de muitas dessas propostas.

A criação de colônias agrícolas com base em referências francesas, de fato, pode ser percebida também ao se estudar planos emancipacionistas. Sob esse aspecto, a atitude de Nabuco de Araújo frente à questão da escravidão é especialmente importante e nos ajuda a apreender a questão. Deve-se dizer, primeiramente, que o próprio tema da escravidão é fortemente vinculado à questão agrária, propriamente dita, uma vez que ela era a forma de produção predominante no setor rural do Brasil Império. De acordo com Eduardo Spiller Penna,

[a] maior parte dos estudos sobre a história agrária do Brasil e das Américas não dissocia a reflexão sobre a estrutura da posse e uso da terra das formas de organização do trabalho produzidas nessas regiões, 
| 266 |

Ordem social e práticas...

desde os primórdios da colonização (PENNA, 2005:

188).

Nas discussões a respeito do projeto do Marquês de São Vicente - incumbido pelo Imperador, em 1866, de apresentar um projeto de lei visando a extinguir gradualmente a escravidão -, Nabuco adotou uma posição favorável a uma emancipação gradual, com medidas moderadas, mas fez também referência à criação de colônias agrícolas. Ao longo do debate e da exposição de suas posições, ele fez várias e importantes alusões à França, sobretudo em relação às colônias francesas. O termo "colônia", aqui, distintamente daquele explicitado mais acima, refere-se a núcleos de povoamento fundados por um povo em território estrangeiro.

Em relação às colônias francesas, é preciso dizer que, no século XIX, elas ainda abrangiam diversas regiões do mundo, sendo que para nosso estudo, ressaltaremos principalmente a região caribenha, as chamadas Antilhas francesas, na América Central, região onde a escravidão dos negros foi mantida - após uma efêmera abolição entre 1794 e 1802 - até 1848, quando foi abolida definitivamente pelo governo da II República francesa (1848-1852) (BUTEL, 2007), devendo-se, contudo, destacar o caso de Haiti, que se libertou do domínio francês em 1804.

Nas Antilhas, antes da abolição haviam sido instituídas leis visando a prepará-las à abolição, sob a Monarquia de Julho. Após 1848, foram experimentadas políticas de incentivo a usinas centrais (BUTEL, 2007) - projeto que seria também endossado por abolicionistas brasileiros, como André Rebouças. Na legislação emancipacionista, percebe-se uma vontade de controlar o processo de transição do trabalho escravo para o livre, de modo que a mesma fosse feita dentro da ordem - preocupação essa que é visível nos projetos brasileiros emancipacionistas, inclusive aqueles em que se percebe a presença de elementos franceses.

Em 1867, foram realizados dois debates no Conselho de Estado do Império do Brasil, para examinar o projeto de emancipação, de autoria do Marquês de São Vicente. É importante frisar que a 
apresentação desse projeto se deu no contexto da repercussão, junto a Dom Pedro II, de uma carta de abolicionistas franceses da Junta Francesa de Emancipação, incluindo personalidades de renome como François Guizot e o Duque de Broglie, pedindo a atuação do Imperador para promover a extinção da escravidão no Brasil. O então presidente do Conselho de Ministros, o liberal Zacarias de Góes e Vasconcelos, sujeitou o projeto ao exame dos conselheiros, formulando também para cada um deles um questionário a respeito da conveniência de se adotar uma lei emancipacionista e dos modos de efetivá-la. Cada conselheiro foi instado a dar seu parecer acerca da proposta de São Vicente, que, grosso modo, previa a libertação dos filhos dos negros escravizados, como uma prévia daquela que viria a ser a Lei do Ventre Livre.

Nabuco de Araújo, em seu pronunciamento relativo ao projeto emancipacionista, na primeira consulta (fevereiro de 1867), adotou uma posição moderada, mas favorável à instituição da medida. Ele refutou a ideia de abolição imediata da escravidão, pregando uma abolição gradual, dentro da ordem estabelecida. Em suas palavras: "Direi que a abolição não deve ser simultânea e imediata, mas gradual. A abolição imediata e simultânea precipitaria o Brasil em um abismo profundo e imenso" (NABUCO, 1997: 711).

Por outro lado, Nabuco, consciente da fragilidade cada vez maior da escravidão no contexto internacional e pessoalmente simpático ao ideal de emancipação, defendeu a importância de se adotar uma medida, até como forma de evitar o risco de convulsões sociais. Em sua argumentação, ele aludiu à experiência histórica de outras nações, inclusive da França, como se pode ver no seguinte trecho:

Esperar, só por esperar, dizia o duque de Broglie, esperar só por irresolução e por falta de corarem para empreender alguma coisa, é o pior dos partidos, é o mais certo de todos os perigos. 
$|268|$

Ordem social e práticas...

Quantos males, diz outro escritor, se teriam prevenido, se em 1843 a abolição fosse decretada nas colônias francesas, logo depois do relatório do duque de Broglie? A abolição da escravidão não teria sido obra da revolução, não se confundiria e complicaria com a revolução (NABUCO, 1997: 710).

Mais adiante, Nabuco ainda afirmou que

[a] França, apesar dos trabalhos profundos, organizados pela comissão presidida pelo duque de Broglie em 1843, não resolveu a questão da emancipação senão indiretamente pela lei de 1845, só relativa ao regime da escravidão. Foi a revolução de 1848 que pronunciou a abolição simultânea e imediata (NABUCO, 1997: 711).

Preocupava-o a possibilidade de uma conflagração social, caso a questão da escravidão não fosse abordada pelo governo, pensamento comum a muitos políticos de seu tempo, que se lembravam da insurreição dos negros haitianos, do início do século. Para ele, "antes as consequências que houve na Martinica e na Guadalupe, do que os precedentes havidos em São Domingos" (NABUCO, 1997: 714). Em outro trecho de sua resposta ao questionário apresentado por Zacarias, Nabuco, abordando as formas de efetivar a lei de emancipação, manifestou sua preocupação com a ordem pública e com a manutenção do trabalho, que, em sua opinião, dificilmente poderia ser garantida logo com a imigração. Nesse sentido, fez referências às Antilhas, então administrada pela França, como se percebe adiante:

A reorganização do trabalho nas Antilhas tem sido coisa bem difícil, sendo que por meios diplomáticos conseguiu a França que fossem elas supridas por seis mil indianos e por africanos. Segundo um importante artigo da Revista dos Dois Mundos, dezembro de 1863, a prosperidade das Antilhas francesas ainda hoje depende da corrente da imigração e da divisão da cultura e fabrico do sistema das fábricas centrais (NABUCO, 1997: 712). 
Percebe-se, acima, a referência a um sistema bastante defendido por personalidades como André Rebouças, isto é, o das fábricas centrais. Deve-se dizer a esse respeito que a Martinica e a Guadalupe, após a abolição da escravidão, foram palco de experiências bem sucedidas, em termos econômicos, de usinas centrais, instaladas em parte com auxílio de crédito fundiário, o Crédit foncier colonial (BUTEL, 2007: 394-400). Nabuco, depois, apresentou, na opinião de seu filho, o "esboço completo da futura lei de 28 de setembro" (NABUCO, 1997: 712) (Lei de 28 de Setembro de 1871, a Lei do Ventre Livre), apoiando a liberdade dos recém-nascidos de mulheres escravas e reconhecendo o direito do escravizado de obter a alforria, mediante o acúmulo de pecúlio, lembrando que a legislação francesa de 1845 e a inglesa de 1831 "garantiam tudo que o escravo adquirisse por doação, sucessão ou testamento" (NABUCO, 1997: 718).

A referência francesa remete às leis de 18 e 19 de julho de 1845, que, na perspectiva de uma extinção gradual da escravidão, apoiada pelo governo da Monarquia de Julho, instituía medidas que em princípio seriam favoráveis aos negros, como a extensão às colônias da Guiana e da Ilha Bourbon do decreto real de 15 de outubro de 1786, possibilitando a concessão de lotes de terras aos negros escravizados da Guadalupe e da Martinica. A abolição seria possível, para Nabuco de Araújo, se fosse gradual, com a liberdade dos recém-nascidos e com o crescimento do número de alforrias. Nabuco, preocupado com os efeitos de aprovação da lei ao seio da população escrava - ele temia "desordens" e a "inércia do trabalho" -, pregou a adoção de algumas medidas, de caráter repressivo:

1o Obrigar os libertos a engajarem seus serviços dentro de um curto prazo com seu antigo senhor ou com outro de sua escolha, sob a pena de serem havidos por vagabundos.

$2^{0}$ Punir os vagabundos e vadios, não com a prisão simples, que é o que eles desejam, mas com o trabalho nos estabelecimentos ou colônias disciplinares.

$3^{\text {o }}$ Criar esses estabelecimentos e colônias. 
| 270 |

Ordem social e práticas...

\begin{abstract}
Senhor! Entre as colônias francesas, houve uma, a ilha da Reunião, que atravessou incólume a perigosa transição da abolição, e foi isto devido principalmente à previdência e perseverança com que o governador obrigou os libertos a tomarem engajamento em dois meses, sob pena de serem havidos por vagabundos e punidos com trabalho nos estabelecimentos disciplinares (NABUCO, 1997: 714).
\end{abstract}

Observa-se a proximidade com o projeto de criação de colônias penais, referido mais acima, e a referência à Ilha da Reunião, administrada pelos franceses, como modelo a ser seguido na relação entre governo e libertos. É preciso observar que Nabuco já estava, aí, abordando a perspectiva da emancipação progressiva do conjunto da população escrava (que viria com as alforrias), e não somente dos recém-libertos. Propôs ele também a remoção dos escravos das capitais para o campo, considerando os interesses da lavoura, e também vislumbrando uma maior "segurança" das cidades.

As medidas propostas por Nabuco inserem-se no debate, já aludido, em torno da repressão à "ociosidade", que era atribuída por vários políticos às classes desfavorecidas da sociedade. De acordo com Fernando Antônio Lourenço,

[r]evelando não poucas afinidades com o liberalismo escravista, a abolição gradual projetada por Nabuco de Araújo como que sumariava um programa de reformas, idealizado pela classe dirigente imperial, para substituir o trabalho escravo por outras formas de trabalho compulsório (LOURENÇO, 2001: 109).

Lourenço considerou, em seu estudo, que o conservadorismo marcou fortemente projetos como o de Nabuco. Porém, como já observamos, acreditamos ser necessário algum cuidado, no caso específico do conselheiro, uma vez que ele já dera mostras concretas de seu emancipacionismo - que se pense, por exemplo, na Lei Nabuco de Araújo (1854), já mencionada. 
Na segunda consulta ao Conselho de Estado em relação ao projeto de São Vicente, em abril de 1867, Nabuco, ao abordar o destino dos recém-nascidos, que seriam considerados livres pela lei projetada, propôs a instituição de colônias agrícolas para menores. Não questionando a possibilidade oferecida pela lei ao senhor de manter o recém-liberto sob seu domínio até a idade dos vinte anos (para homens) e dezoito (para mulheres), Nabuco interpelou o item da lei que previa que os filhos de escravos fossem mantidos por associações, no caso em que os senhores se recusassem a mantê-los sob seu controle até as idades referidas. Para o conselheiro, essas associações, ou sociedades, poderiam dispor do trabalho gratuito das crianças (como ocorreria caso fossem mantidas junto aos senhores), em colônias agrícolas, cujo modelo poderia ser buscado em países como a França. Segundo Nabuco,

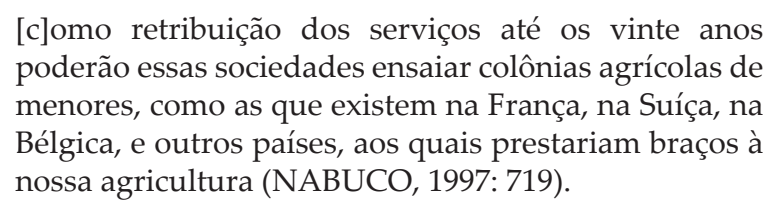

A criação de colônias agrícolas de menores foi uma medida que foi defendida por amplos setores políticos e intelectuais brasileiros. Sônia Mendonça, em O Ruralismo Brasileiro (1888-1931), teceu importantes comentários a respeito, analisando a formação de estabelecimentos de ensino agrícola associados a um sistema repressivo - os "patronatos agrícolas" -, já na Primeira República (MENDONÇA, 1997: 167), também examinados por Adriana de Resende Vianna. Esta autora mostrou como o trabalho agrícola, que ela estudou tendo como foco os menores, esteve associado a propostas que, de alguma forma, previam o trabalho compulsório. Segundo Vianna,

[...] é importante não perder de vista que o espaço rural só era representado como comportando uma forte dimensão ordenadora porque se pretendia que sua ocupação se desse através de esquemas rígidos 
| 272 |

Ordem social e práticas...

de controle sobre a população para lá deslocada (VIANNA, 1999: 79).

Percebe-se a semelhança com as teses defendidas por Lourenço. Independente das convicções pessoais de Nabuco de Araújo, a proposta de criação de colônias para menores inserese num debate amplo, em que esta tendia ser apoiada como uma medida de controle e de ordem social, e, no período de transição da escravidão para o trabalho livre, como forma de controlar a população liberta. Deve-se lembrar, ainda, que sob o Império, a Lei dos Sexagenários, aprovada em 1885, previu, em seu artigo $4^{\circ}$, a criação de colônias agrícolas, para onde deveriam ser enviados os "libertos sem ocupação".

No debate do Conselho de Estado, Nabuco posicionou-se em relação aos outros itens do projeto emancipacionista, ora apoiando, ora criticando algumas medidas. Como se percebe, verificou-se uma forte presença de elementos franceses no discurso de Nabuco, que, em 1868, foi escolhido relator do projeto de São Vicente. O diálogo com os autores franceses pode ser percebido quando se examinam as fontes de que se serviu para elaborar seu relatório. De acordo com seu filho Joaquim Nabuco,

[o] que Nabuco fez foi um trabalho puramente de coordenação, de seleção, de graduação e montagem de idéias[sic], sugeridas ou nos projetos de São Vicente (lei portuguesa), ou nas duas reuniões, de 2 e 9 de abril de 1867, do Conselho de Estado, ou na obra de Perdigão Malheiro, que contém os projetos até então apresentados em matéria de escravidão, ou nos trabalhos das comissões francesas de que foram relatores Tocqueville e o duque de Broglie (NABUCO, 1997: 728) [...]

Observa-se a referência francesa, ao lado de outras diversas. Joaquim Nabuco citou, ainda, dentre os franceses, os relatórios Jules Lechevalier (1844), as obras de Victor Schoelcher e de Auguste Cochin. Dentre os brasileiros que lhe serviram de inspiração, merece destaque o nome de Tavares Bastos. Schoelcher, como se sabe, teve 
uma atuação especialmente marcante na França oitocentista, tendo tido um papel fundamental na abolição da escravidão nas colônias francesas, decretada logo após a vitória da Revolução de 1848.

A proposta de emancipação gradual ganhou apoio ao seio da elite política imperial, e seria retomada pelo gabinete do Visconde de Rio Branco, culminando, em 28 de setembro de 1871, com a aprovação da Lei do Ventre Livre, defendida por Nabuco (ANDRADE, 1987: 22-23).

Ao longo dos anos, a proposta gradualista de extinção do cativeiro se firmaria, mais do que uma efetiva política de criação de colônias voltadas para os libertos. Na década de 1880, na iminência da abolição da escravidão - ocorrida oficialmente com a Lei Áurea, em 1888 -, ideias de fixar os negros libertados em colônias, de cunho militar, como forma de garantir a "ordem", seriam manifestadas ao seio da elite política imperial, e um exemplo disso é a projeção de colônias agrícolas pelo já mencionado artigo $4^{\circ}$ da Lei dos Sexagenários - deveriam adotar uma rigidez militar. Note-se, porém, que o movimento abolicionista chegou a formular planos concretos de criação de colônias agrícolas, desta vez tendo como foco não apenas os libertos, mas o conjunto de populações desfavorecidas na área rural - como os indígenas -, uma temática que tem sido aos poucos mais pesquisada e que, por uma questão de limites, apenas assinalamos aqui, antes de concluirmos nosso texto com observações gerais sobre as questões levantadas.

Pelo que se pôde examinar resumidamente, percebe-se, ao lado de alusões a outros modelos externos - é importante frisar a presença de comentários relativos às experiências de outros países, como os Estados Unidos -, que a referência francesa presente nos documentos abordados concernentes ao projeto de colônias agrícolas, ao menos na parte que toca à emancipação, parece ter contribuído no debate acerca da transição do trabalho escravo para o trabalho livre, fornecendo subsídios - em termos teóricos e de experiências concretas - à elite política imperial para conduzir esse processo histórico dentro de um espírito "ordeiro", afastando-se o espectro das convulsões sociais. Em relação à emancipação, realmente, a legislação francesa (e a política relativa 
às colônias daquele país), ao que se vê, serviu de referência para fundamentar uma política de extinção gradual da escravidão, sem abalos e convulsões temidas pelo governo imperial.

Em relação às colônias penais, transparece também nitidamente a preocupação com a ordem. As alusões francesas, nesse caso, parecem ter ajudado na elaboração de projetos de reforma do sistema penitenciário, ao lado de outras referências externas. Concretamente, porém, os projetos reformistas não lograram concretizar-se durante o período imperial, ao menos considerando-se as informações contidas nos relatórios ministeriais focados, uma das principais bases da nossa pesquisa. Seria, sim, instituído um novo Código Penal (em substituição ao de 1830), mas já na República, em 1890.

Em relação às colônias penais, propriamente ditas, apenas uma parece ter sido efetivamente implantada, isto é, a da Ilha de Fernando de Noronha (PE). No entanto, não dispomos, em nossa pesquisa, de dados que comprovem uma vinculação direta entre a criação desta colônia e as experiências francesas, embora seja lícito supor que essa vinculação tenha existido, dado o fato de que os setores governamentais estavam bastante antenados com o que se passava na Europa, especialmente na França. Por outro lado, no período republicano, seriam instituídas diversas colônias penais e agrícolas, dentre as quais as da Ilha Grande (RJ), sob certos aspectos com características parecidas às das suas congêneres francesas. Uma pesquisa ulterior, mais aprofundada, poderia eventualmente demonstrar uma conexão direta entre essas experiências e a das colônias implantadas na França, que, conforme observado, foram numerosas.

Deve-se, ainda, observar a referência à prática de métodos agrícolas "científicos" e "modernos" ao seio das colônias penais e agrícolas francesas, ao menos em Mettray, que foi a mais famosa delas, conforme observado por Ivan Jablonka, e que, conforme visto, foi citada pelos políticos do Império brasileiro. Essa observação é importante, pois denota a preocupação, entre as elites políticas imperiais, em apoiar-se em projetos baseados em ideais de modernidade e, mais até, numa noção de civilização. As 
referências francesas parecem ter, na verdade, ajudado a legitimar um discurso fortemente vinculado a um ideário de civilização, e também de modernização conservadora, isto é, de reformas dentro da ordem, sem abalar a estrutura social hierárquica.

Enfim, deve-se ressaltar a ideologia liberal, que permeou o discurso dos políticos e estadistas do Segundo Reinado, e ter em mente o fato que a mesma conseguiu conciliar a defesa da ordem e da propriedade privada com um discurso favorável a reformas - ainda que moderadas. Sob esse ponto, é interessante destacar o estudo de René Rémond, que mostrou como a ideologia liberal oitocentista possuía um autêntico traço idealista, ao mesmo tempo em que podia ser claramente associada a interesses específicos de classe (RÉMOND, 1974). Vendo por esse prisma, pode-se pensar que a preocupação com a ordem, claramente presente nos projetos de colônias agrícolas examinados, podia denotar fundamentalmente uma preocupação com a manutenção da estrutura social hierarquizada ou vincular-se a uma real preocupação de justiça social ou, ainda, as duas coisas simultaneamente.

\section{Referências}

ANDRADE, M. C. Abolição e Reforma Agrária. São Paulo: Editora Ática, 1987.

ASSELAIN, J. Histoire économique de la France: du XVIIIe siècle à nos jours. Volume 1. De l'Ancien Régime à la Première Guerre Mondiale. Éditions du Seuil, 1984.

BOTELHO, A. V.; REIS, L. M. Dicionário Histórico Brasil: Colônia e Império. Belo Horizonte: O Autor, 2001.

BUTEL, P. Histoire des Antilles françaises. XVII-XXe siècle. Éditions Perrin, 2007.

CORELLI, M. Culturas Cruzadas: Intercâmbios culturais entre França e Brasil. Campinas: Papirus, 1994. 272p.

FERREIRA, T. M. B. C. Bibliotecas de médicos e advogados do Rio de Janeiro: dever e lazer em um só lugar. In. ABREU, M. 
(Org.). Leituras, História e Memória da Leitura. Campinas, SP: Fapesp / Mercado das Letras/ ALR, 1999.

FIRMO, J. S.; OCTACIANO, N. Parlamentares do Império. Brasília: Senado Federal, 1973.

FOUCAULT, M. Vigiar e Punir. 35aㅡ ed. Petrópolis: Vozes, 2008.

FOUGÈRE, É. Le grande livre do bagne: en Guyane et Nouvelle Calédonie. Saint-Clotilde (Ilha da Reunião): Ed. Orphie, 2002.

GREGORY, V. Colônia. In. MOTTA, M. M. M. (Org.). Dicionário da Terra. Rio de Janeiro, RJ: Civilização Brasileira, 2005, pp.96-98.

GUIMARÃES, A. P. Quatro Séculos de Latifúndio. 6" ed. Rio de Janeiro, RJ: Paz e Terra, 1989.

JABLONKA, I. L'éducation des jeunes détenus à Mettray et dans les colonies agricoles pénitentiaires françaises (1830-1900). In. CHASSAT, S. ; FORLIVESI, L. ; POTTIER, G. Éduquer et punir: la colonie agricole et pénitentiaire de Mettray (1839-1937). Rennes: Presses Universitaires de Rennes, 2005, pp. 69-79.

JORNAL DO COMMERCIO. Jornal do Commercio: a notícia do dia a dia, 1827-1987. Reprodução da $1^{a}$ página do Jornal do Commercio de 15/3/1878.

KNITTEL, F. Agronomie et innovation. Le cas Mathieu de Dombasle (1777-1843). Nancy: Presses Universitaires de Nancy, 2009.

LOURENÇO, A. F. Agricultura Ilustrada: Liberalismo e escravismo nas origens da questão agrária brasileira. Campinas, SP: Editora da Unicamp, 2001.

MENDONÇA, S. R. O Ruralismo Brasileiro (1888-1931). São Paulo: Hucitec, 1997.

MOTTA, M. M. M. Nas fronteiras do poder: conflito e direito à terra no Brasil do século XIX. Rio de Janeiro, RJ: Vício de Leitura / Arquivo Público do Estado do Rio de Janeiro, 1998.

MOULIN, A. Les paysans dans la société française. De la Révolution à nos jours. Éditions du Seuil, 1988. 
NABUCO, J. Um Estadista do Império. 2 volumes. 5. ed. Rio de Janeiro, Topbooks, 1997.

PENNA, E. S. Escravidão. In. MOTTA, M. M. M (Org.). Dicionário da Terra. Rio de Janeiro, RJ: Civilização Brasileira, 2005.

PRADE, C. Les colonies pénitentiaires au XIXe siècle: de la genèse au déclin. In. CHASSAT, S.; FORLIVESI, L.; POTTIER, G. Éduquer et punir: la colonie agricole et pénitentiaire de Mettray (1839-1937). Rennes: Presses Universitaires de Rennes, 2005, pp. 27-37.

RELATÓRIO DO MINISTÉRIO DA JUSTIÇA. Rio de Janeiro. Anos de 1866, 1874 e 1875.

RÉMOND, R. Le XIXe siècle. 1815-1914. Paris: Éditions du Seuil, 1974.

SANTOS, M. S. Os porões da República: a barbárie nas prisões da Ilha Grande (1894-1945). Rio de Janeiro, RJ: Garamond, 2009.

SCHAPOCHNIK, N. Das ficções do Arquivo: ordem dos livros e práticas de leitura na Biblioteca Pública da Corte Imperial. In. ABREU, M (Org.). Leitura, História e Memória da Leitura. Campinas, SP: Fapesp / Mercado de Letras / ALR, 1999, pp. 301-310

VIANNA, A. R. O mal que se adivinha: polícia e menoridade no Rio de Janeiro, 1910-1920. Rio de Janeiro, RJ: Arquivo Nacional, 1999. 